\title{
Development of Cyclic-CIP and its Application to Powder Forming
}

\author{
Yohtaro MATSUO, Toshiyuki NISHIMURA, Katsuhisa JINBO* \\ Kouichi YASUDA and Shiushichi KIMURA \\ Department of Inorganic Materials, Faculty of Engineering, Tokyo Institute of Technology \\ 2-12-1, Ookayama, Meguro-ku, Tokyo 152 \\ * Department of Mechanical Engineering for Production, Faculty of Engineering, Tokyo Institute of Technology
}

\section{サイクリック CIP の開発とセラミック成形体密度の向上}

\author{
松尾陽太郎・西村聡之・神 保勝久*·安田公一・木村脩七 \\ ( 東京工業大学 工学部 無機材料工学科) \\ *東京工業大学 工学部 生産機械工学科)
}

\begin{abstract}
The authors developed a new powder forming technique, called as "Cyclic Cold Isostatic Pressing (C-CIP)", by superimposing cyclic pressure wave onto a static hydraulic pressure. Using this method, we performed dry powder forming on two kinds of alumina powders which have different compaction characteristics, and measured the bulk density and the hardness of the green compacts. The green density increased remarkably as the number of repeating times of pressure increased. The rate of increasing density against the repeating times became larger as the maximum pressure became higher. The micro-Vickers hardness for slightly calcined body, which is closely connected with the green compacts, increased remarkably as the repeating times increased. Employing our new method, we can make the CIP pressure remarkably low in comparison with the ordinary CIP.
\end{abstract}

[Received September 28, 1987; Accepted October 22, 1987]

Key-words : Cyclic CIP, Powder forming, Alumina green compacts, Density, Micro-Vickers hardness

\section{Introduction}

If we can obtain the homogeneous green compacts with high density, the shrinkage at sintering may become smaller and the sintering temperature may be drawn down. Then, the material properties and their reliability may increase, which may significantly affect the development of advanced ceramics.

The most popular powder-forming process is the dry-uniaxial pressing. Since this method can be operated fully automatically, it is suitable for mass production. However, the green compacts produced by this method may often be heterogeneous in density because of the friction between die and green compacts, the bridging phenomenon among particles and the nonuniformity of the pressure, which may cause cracks, distorsion, lamination, and other defects to the sintered body. ${ }^{1)}$ On the other hand, socalled vibratory uniaxial forming methods was developed in order to eliminate the friction between the die and the powders. In this manner, the mobility of powder under pressure is increased and compaction is accelerated. ${ }^{2)}$ Bell et al. investigated the vibratory forming method on the compaction of $\mathrm{Al}_{2} \mathrm{O}_{3}, \quad 30 \mathrm{Cr}-70 \mathrm{Al}_{2} \mathrm{O}_{3}, \quad 15 \mathrm{Ni}$ -
$85 \mathrm{TiC}$ powder, and suggested that the compacts having similar property to that prepared by CIP can be obtained by low-frequency vibration. ${ }^{3)}$ In addition, they insisted that the vibratory forming method had the following advantages: (a) No binder is required, (b) the method is considerably faster on a laboratory scale, (c) less equipment is required, and (d) compacts with complicated shape can be prepared by only one operation. Kobayashi indicated that by vibratory forming of $\mathrm{Al}_{2} \mathrm{O}_{3}$ powder in $60 \mathrm{~Hz}$, high-density compacts could be obtained in the forming pressure of $1 / 10$ to $1 / 20$ of that of ordinary uniaxial pressing. ${ }^{4)}$ However, the vibratory forming may not be adequate to form the large-sized thick compacts and cylindrical compacts.

While, the cold isostatic forming method enables the preparation of comparatively homogeneous and large-sized compacts by filling up the powder into deformable forming die and applying isostatic pressure. This method is called as cold isostatic pressing (CIP). James studied the CIP-forming of metal powder and suggested that the plastic deformation started immediately after applying pressure. ${ }^{5)}$ Beddow investigated the CIP-forming of copper powders with different- 
ly shaped particles, and found that the green density did not increase any more for the particles of various shaped, when the forming pressure exceeded a certain level. This must indicate that the plastic deformation starts at fairly initial stages of compaction. ${ }^{6)}$

Abe et al. studied the CIP-forming of $\mathrm{SiC}$ powder, and measured the density distribution and microhardness distibution of the green compacts. The close relationship was found between the both distributions, suggesting that it depended on the shape of compacts and the pressure. $^{\text {7) }}$

However, the ordinary CIP procedure requires a high pressure such as $600-900 \mathrm{MPa}$ to obtain homegeneous and high-density green compacts. Therefore, the CIP devices have been becoming larger.

Thus, we developed a new forming procedure, named as cyclic-CIP procedure, in which the advantages of the vibratory forming and hydrostatic forming techniques were combined. Using this procedure, we confirmed the improvement of the packing density of the formed green compacts. In addition, we investigated the property of the green compacts of $\mathrm{Al}_{2} \mathrm{O}_{3}$ obtained by this procedure.

\section{Development of cyclic-CIP device}

In ordinary CIP procedure, the pressure may be applied as follows; First, the pressure is increased by a pump, and is kept for a certain time at a maximum pressure and then released (Fig. 1 (a)). However, this procedure requires extremely high pressure due to the influence of bridging phenomenon etc in order to obtain high green density. Therefore, we newly developed the so-called "cyclic-CIP (abbreviated as C-CIP)" procedure using a pressure pattern illustrated in Fig. 1 (b). In this procedure, first of all, a certain degree of bias pressure $P_{0}(\geqq 0)$ is applied. Then, a cyclicly varying pressure is superimposed (maximum pressure $: P_{\max }$ ). After repeating for a certain times, superimposed cyclic pressure is stopped and finally the bias pressure is released. Using this technique, it is expected to obtain high-density green compacts even at relatively low pressure $P_{\max }$.

The system of this device is consisted of a servo valve, a booster, a pressure vessel, an oilpressure unit, a back pressure unit, a pressure transducer and a servo controller. The schematic diagram is shown in Fig. 2. The output of the function generator works as reference input, and the pressure applied on a specimen works as controlled variable. When the difference between the reference input and controlled variable (error signal) is amplified and input into the servo valve, the spool moves proportinal to the degree of input signal, and pressured fluid is input into the booster from oil pressure unit. The pressure boosted to high pressure range is detected by a pressure transducer and feedbacked to the servo controller. When the actuating error signal becomes zero, the spool returns to the neutral position, so that the pressure equivalent to the reference input is always applied on a specimen. This device provides a maximum cyclic pressure : $500 \mathrm{MPa}$, and a maximum cyclic frequency: $10 \mathrm{~Hz}$.

\section{Characterization of powder}

The powder used in this experiment is low soda reactive alumina (AL-160 SG and AL-150 SG produced by Showa Keikinzoku Co., Ltd. ). AL-160 SG has average grain size $: 0.4 \mu \mathrm{m}$, purity : $99.58 \%$ and real density : 3.90 , while, AL-150 SG has $2.0 \mu \mathrm{m}, 99.9 \%$ and 3.92 , respectively. In the analysis of powder X-ray diffraction, the main component was found to be $\alpha-\mathrm{Al}_{2} \mathrm{O}_{3}$

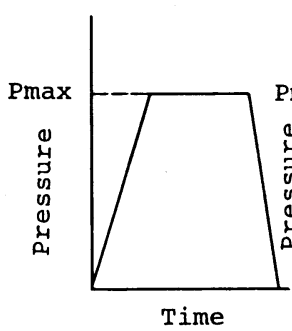

(a) ordinary CIP

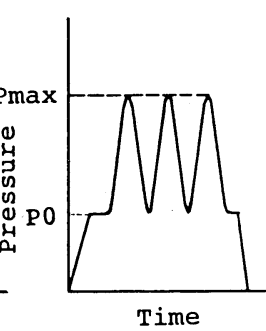

(b) C-CIP

Fig. 1. Comparison between CIP and CCIP in pressurizing pattern.

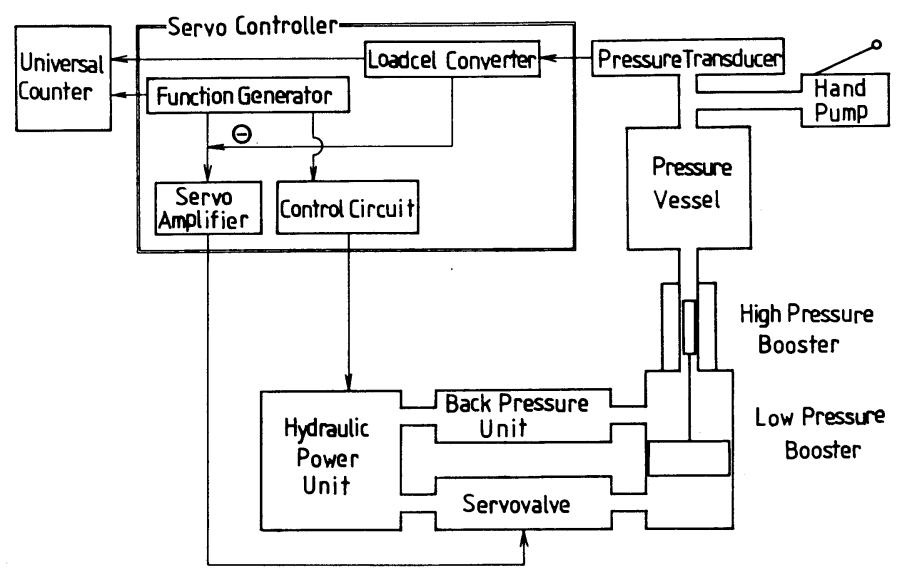

Fig. 2. Schematic of cyclic-CIP. 


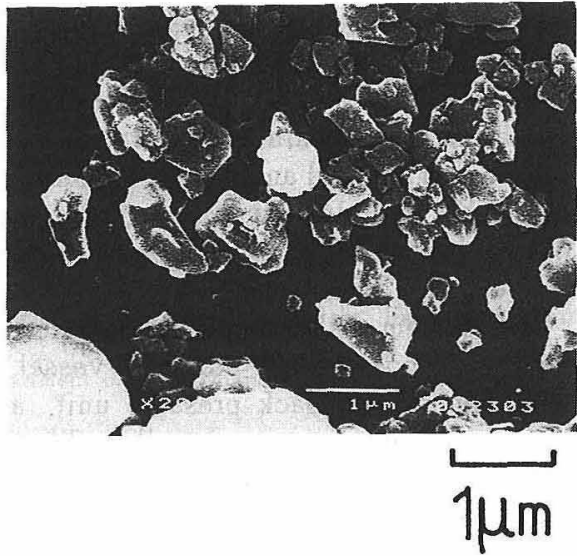

(a ) AL-150 SG

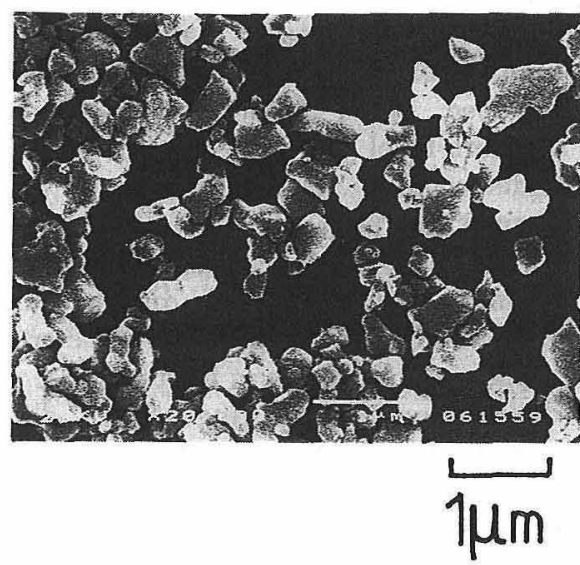

(b) AL-160 SG

Fig. 3. SEM micrographs of alumina powders.

for both kinds of powders.

Figure 3 shows SEM photographs of the powders. The photographs show a large number of primary particles of about $0.5 \mu \mathrm{m}$ in size, and make the secondary particles of a few or over ten micronmeters. The shape of the particles looks non-uniform, and agglomeration of primary particles is found to be loose.

In AL-150 SG, the particles with submicron to comparatively large such as a few micron are observed, indicating that it has a wide particle size distribution. Further, similar to AL-160 $S G$, the agglomeration of particles can be seen. In the experiment mentioned above, each alumina powder was used separately without adding additives such as lubricant or binder.

\section{Experimental procedures}

Three kinds of specimens were prepared as follows:

(1) Rectangular-shaped specimen of $5 \times 6 \times$ $50 \mathrm{~mm}$ (Specimen A),

(2) Cylindrical-shaped specimen of $\phi 11 \times$ $10 \mathrm{~mm}$ (Specimen B),

( 3 ) Cylindrical-shaped specimen of $\phi 30 \times$ $30 \mathrm{~mm}$ (Specimen C),

These specimens were pre-formed by uniaxialpressing under the pressure of $10 \mathrm{MPa}$ for $30 \mathrm{~s}$. The green density was estimated by measuring the specimen size and weight. The specimen was then put in a latex baloon, closed the opening under vacuum, and followed by cyclic-CIP pressing. The conditions of C-CIP used in the experiment is as follows:

* Maximum pressure $\left(P_{\max }\right): 100,150$, $200 \mathrm{MPa}$

* Bias pressure $\left(P_{0}\right): 40 \%$ of maximum pressure

* Frequency : $1 \mathrm{~Hz}$
* Repeating times: $10,50,100,1000,10000$

For comparison, the ordinary CIP (one-time CIP) was performed by following conditions.

* Pressure : 50, 100,150,200, 250, $300 \mathrm{MPa}$

* Keeping time at each pressure : 2 min.

However, the ordinary CIP (called one-time CIP) is treated also as one time of repeating times in $\mathrm{C}$-CIP.

Some deformations were found on the specimens after CIP forming, so that those specimens in which an accurate size cannot be measured, were polished by a SiC abrasive paper \#1200. The green density was then calculated by their size and weight.

The specimens $\mathrm{A}$ and $\mathrm{C}$ used in the density measurement were calcined in $1000^{\circ} \mathrm{C}$ for $30 \mathrm{~min}$ and $1 \mathrm{~h}$, respectively. Specimen $\mathrm{A}$ was cut into two pieces at around the center part along longitudinal direction, polished the cross section, then Vickers indentation was followed. Specimen $\mathrm{C}$ was cut at the center section and at the section of $7 \mathrm{~mm}$ apart from the edge surface. After polishing the cross section, microhardness

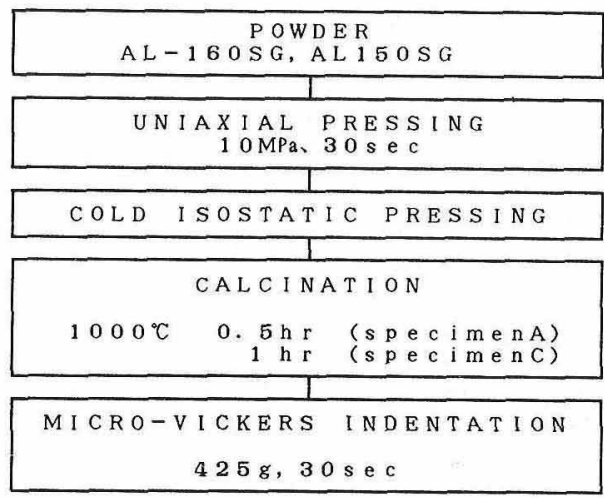

Fig. 4. Flow chart of experimental procedure. 
was measured by Vickers indentation. Flow chart of the experimental procedures is illustrated in Fig. 4.

\section{Experimental results}

The relative density of the specimen after pre-forming (pressure : $10 \mathrm{MPa}$, uniaxial pressing) was $42-47 \%$ for $\mathrm{Al}-160 \mathrm{SG}$ and $55-58 \%$ for AL-150 SG.

CIP pressure versus density change of specimen $\mathrm{B}$ formed by one-time CIP procedure is shown in Fig.5. The packing ability of AL-150 SG is better than that of AL-160 SG, accordingly, AL-150 SG shows the relative density $66.8 \%$ at $300 \mathrm{MPa}$.

The effect of repeating times and the maximum pressure on the density of AL-160 SG compacts (specimen A) formed by C-CIP procedure, is shown in Fig. 6. In this experimental range, the green density increases linearly against the log

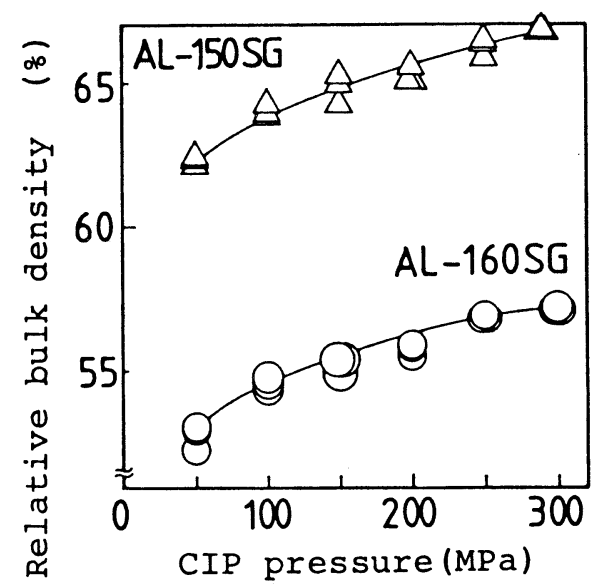

Fig. 5. Increase in bulk density by ordinary CIP.

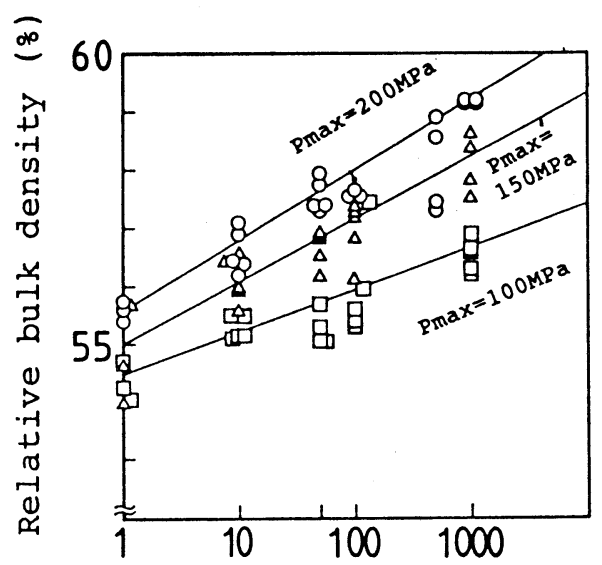

$$
\text { Repeating times (times) }
$$

Fig.6. Increase in bulk density of AL-160 SG compact by C-CIP. scale of repeating times. This suggests that the effect of cyclic pressure is significantly remarkable. Figure 7 shows the effect of repeating times on the density of the green compacts and calcined specimens of specimen C (AL-150SG and AL-160 SG) formed by C-CIP procedure. The maximum pressure $P_{\max }$ was $200 \mathrm{MPa}$. There is no difference between the two procedures in Fig. 7. Therefore we regard the Vickers microhardness as a substitute of the packing density.

Figure 8 shows the distribution of the microVickers hardnees of AL-160 SG calcinated specimen (specimen A, calcinated at $1000^{\circ} \mathrm{C}$ for $30 \mathrm{~min}$, formed by C-CIP in $P_{\max }=200 \mathrm{MPa}$ ) - The hardness extremely increases with the increase of repeating times, and the hardness distribution in the specimen seems to be homogeneous. The relationship between the de-

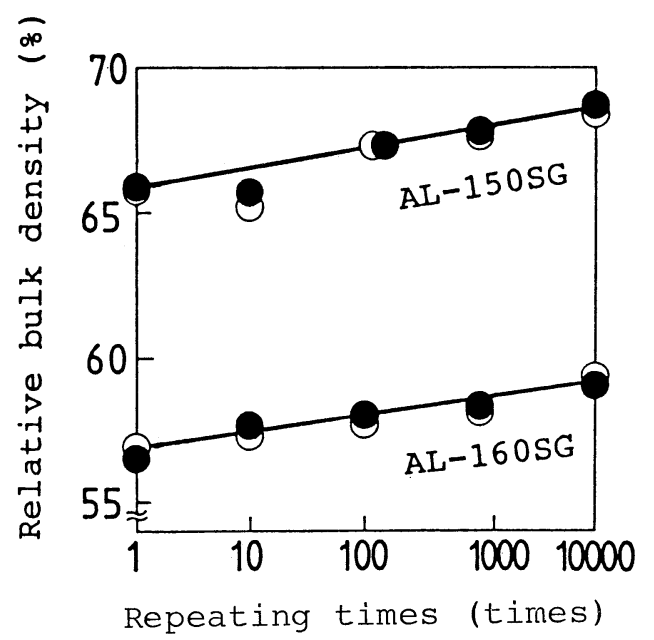

Fig. 7. Increase in bulk density of specimen $\mathrm{C}$ by $\mathrm{C}$ CIP $\left(P_{\max }=200 \mathrm{MPa}\right)$.

$\bigcirc$ Compact of C-CIP, Compact of calcined

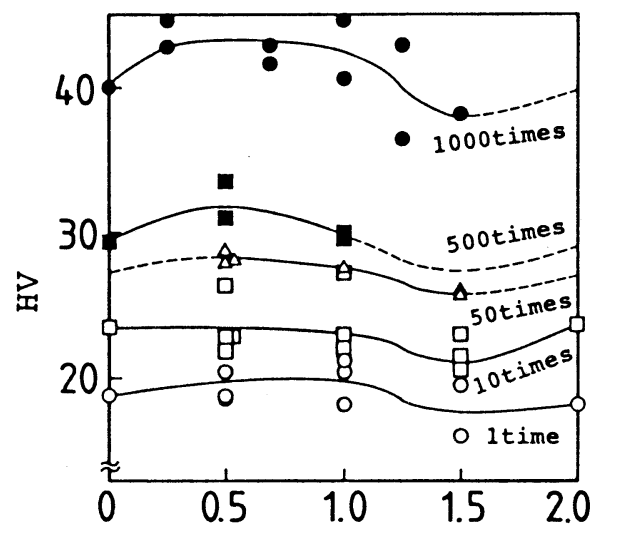

Distance from center (mm)

Fig. 8. Micro-Vickers hardness distribution of specimen A (AL-160 SG), $P_{\max }=200 \mathrm{MPa}$. 


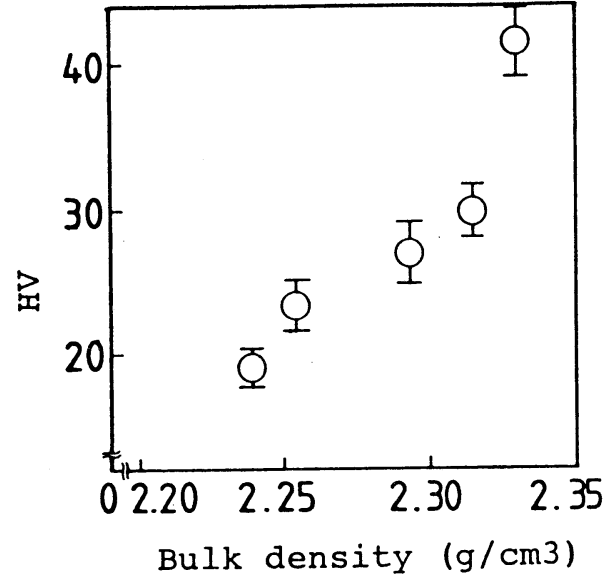

Fig. 9. $H_{\mathrm{v}}$ vs bulk density of calcined AL-160 SG compacts.

nsity and the average value of hardness of specimen $A(A L-160 S G)$ is given in Fig. 9. Approximately a proportional relationship can be seen between the two variables. Hardness distribution was also measured on the specimen $\mathrm{C}$ which is bigger in size than specimen $A$. The results is shown in Fig. 10. Almost uniform distribution can be found with a little fluctuation.

\section{Discussion}

The green density of the compacts formed by ordinary CIP increases with CIP pressure, but the rate of increase becomes smaller as the pressure increases. On the other hand, the green density of the compacts formed by C-CIP increases with the increase of repeating times as shown in Figs. 6 and 7. The higher the cyclic pressure, the higher the rate of increase in density. The effect of repeating times is remarkable in AL-150 SG, which has a higher packing ability of the powders than in AL-160 SG. The packing density may increase further by increasing the repeating times more than 10000 times. However, the relative density should be saturated with the increase of repeating times at some extent.

Generally speaking, in the process of compaction of powders consisted of agglomerated particles (secondary particles), the following three steps may occur. ${ }^{8)}$

(1) Displacement of the relative position of each particle.

( 2 ) Collapsing of secondary particles (disappearance of bridging).

(3) Plastic deformation of particles.

From Figs. 6 and 7, the Steps 1 and 2 are supposed to proceed cumulatively. Especially, the movement of the particles occurs when the press-

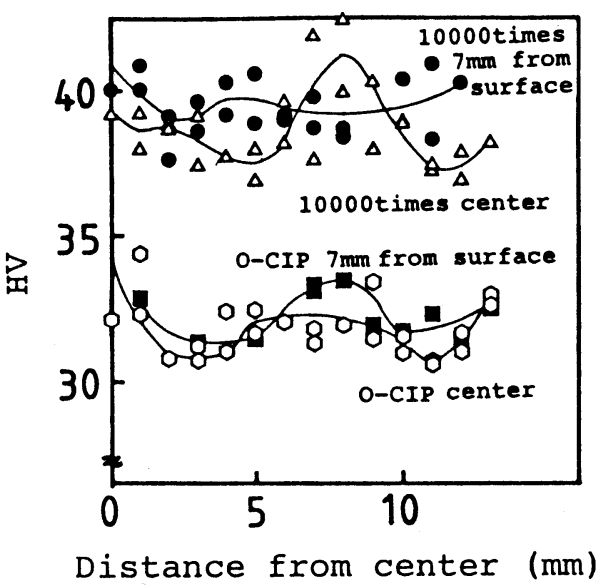

Fig. 10. Micro-Vickers hardness distribution of specimen C (AL-160 SG), $P_{\max }=200 \mathrm{MPa}$.

ure is released from $P_{\max }$ to $P_{0}$, and so the Step 1 is accelerated. In ordinary CIP procedure, the bridging may be more tight since hydrostatic pressure is still applied even when the bridging occurs. While, in C-CIP procedure, in addition to Step 1, the energy to cut off the bonding between the primary particles is supplied by pressure change, therefore the collapsing of secondary particles is considered to be accelerated.

In the ordinary powders including metallic and high polymer powders, the Steps 1 to 3 proceed only up to a certain stage in the case of ordinary CIP procedure, however, in C-CIP procedure, the Steps 1 to 3 are considered to proceed. From the facts mentioned above, the effect of the increase of repeating times in C-CIP procedure is more effective at a certain pressure level than that of the increase of pressure in ordinary CIP procedure. Therefore, we can make the C-CIP pressure remarkably low in comparison with that of the ordinary CIP.

\section{Conclusions}

(1) Cyclic-CIP system, in which cyclic pressure is superimposed onto ordinary CIP pressure, has newly developed by the authors.

(2) $\alpha-\mathrm{Al}_{2} \mathrm{O}_{3}$ green compacts with high density were obtained at comparatively low pressure by using the newly developed cyclic-CIP procedure.

(3) The green density was increased by increasing repeating times.

(4) The effects of repeating times on the green density became more remarkable as the maximum pressure increased.

Acknowledgement The authors wish to sincerely thank Mr. H. Tanaka, Mr. T. Takahashi and Mr. M. Shikano of 
Fujikoshi Co. Ltd., for their technical support. Thanks are also due to Mr. S. Ohsawa for preparation of the manuscript.

\section{References}

1) N. Umeda and T. Mikage, "Ceramic Processing: Powder Preparation and Forming”, Ed. by the Ceramic Society of Japan (1984) pp. 200-05.

2) Y. Shiraki, "Production Process of Ceramics II (in Japanese)", Gihodo (1978) pp. 137-53, 153-79.

3) W.C. Bell, R.D. Dillender, H.R. Lominac and E.G.
Manning, J. Am. Ceram. Soc., 38, 396-404 (1955).

4) H. Kobayashi, Extended Abstracts of 1986 Annual Meeting of The Ceramic Society of Japan (1986) pp. 109-10.

5) P. J. James, Powder Metallurgy, 20, 199-204 (1977).

6) J.K. Beddow, Int'l. J. of Powder Metallurgy, 9, 127-31 (1973).

7) O. Abe, S. Iwai, S. Kanzaki, M. Ohashi and H. Tabata, Yogyo-Kyokai-Shi, 94, 74-80 (1986).

8) "HIP and CIP", Ed. by P. J. James, Nikkan-KogyoShinbun-Sya (1986) pp. 15-21. 